\title{
Leopoldina: primeira cultivar de grão-de-bico para Minas Gerais.
}

\author{
Rogério F. Vieira ${ }^{1}$; Maria Aparecida V. de Resende ${ }^{1}$; Clibas Vieira ${ }^{2}$ \\ ${ }^{1}$ Epamig, Vila Gianetti, 47, 36.571-000 Viçosa-MG; ${ }^{2}$, UFV-Dept ${ }^{\circ}$ de Fitotecnia, 36.571-000 Viçosa-MG.
}

\section{RESUMO}

A cultivar de grão-de-bico Leopoldina foi introduzida do "International Center for Agricultural Research in the Dry Areas" (ICRISAT), localizado na Índia, com a denominação ICCV-3. Suas sementes têm coloração creme (tipo kabuli) e o peso de 100 unidades varia de 28 a $36 \mathrm{~g}$. Apresenta plantas com tipo de crescimentos ereto e inserção da primeira vagem alta. As plantas podem atingir $60 \mathrm{~cm}$ de altura. Seu ciclo de vida varia de 125 a 135 dias. É resistente à raça 1 do Fusarium oxysporum f. sp. cicero e tolerante aos nematóides causadores de galhas nas raízes. Nos ensaios conduzidos no outono-inverno com irrigação na Zona da Mata e no Norte de Minas Gerais, os rendimentos alcançados pela 'Leopoldina' variaram de 2.037 a $2.950 \mathrm{~kg} / \mathrm{ha}$.

Palavras-chave: Cicer arietinum, Fusarium oxysporum $f$. $s p$. cicero, nematóides, ciclo de vida, rendimento.

\section{ABSTRACT}

Leopoldina: first chickpea cultivar for Minas Gerais State, Brazil.

'Leopoldina' was introduced from the International Center for Agricultural Research in the Dry Areas (ICRISAT), Índia, as line ICCV-3. The seeds are cream (kabuli type) and 100-seed weight ranges from 28 to $36 \mathrm{~g}$. 'Leopoldina' has erect plant type and high first pod insertion. The plant can reach $60 \mathrm{~cm}$ in height, and its life cycle ranges from 125 to 135 days. 'Leopoldina' is resistant to race 1 of Fusarium oxysporum f.sp. cicero and tolerant to root-knot nematodes. In trials carried out during fall-winter with irrigation at "Zona da Mata" and "Norte" regions of Minas Gerais, Brazil, yields varied from 2,037 to $2,950 \mathrm{~kg} / \mathrm{ha}$.

Keywords: Cicer arietinum, Fusarium oxysporum $f s p$. cicero, nematodes, life cycle, yield.

\section{(Aceito para publicação em 27 de agosto de 1999)}

O grão-de-bico pode ser classificado em dois grupos de cultivares: kabuli e desi. Este último grupo, que predomina na Índia - o maior produtor dessa leguminosa -, não é comercializado no Brasil. As cultivares pertencentes ao grupo kabuli possuem grãos de cor creme com baixo teor de fibras. O consumidor brasileiro tem preferência pelas cultivares de grãos médios e grandes do grupo kabuli, os quais são consumidos na forma de salada ou de pasta. As temperaturas ótimas para o cultivo do grãode-bico estão entre 15 e $30^{\circ} \mathrm{C}$ (Braga et al., 1992). Por isso, no sudeste do Brasil, ele deve ser cultivado no outono-inverno, com irrigação.

A primeira cultivar lançada no Brasil ocorreu em São Paulo, em 1989. A 'IAC Marrocos', introduzida em 1964 do Marrocos, tem grãos de tamanho médio (26 g/100 unidades) e ciclo de vida de 125 a 140 dias (Braga et al., 1992). Em 1994, a cultivar Cícero (grãos grandes), selecionada de introduções procedentes do México, foi recomendada para cultivo no inverno nas condições edafoclimáticas do Brasil Central, onde o seu ciclo de vida é de, aproximadamente, 110 dias (Giordano \& Nascimento, 1994). Minas Gerais tem grande potencial para o cultivo do grão-de-bico, por causa da vasta área irrigada por aspersão e do clima ameno no outono-inverno na maior parte do estado. No entanto, não há cultivar recomendada para as condições edafoclimáticas de Minas Gerais. Logo, 'Leopoldina' é a primeira cultivar a ser lançada para esse estado.

\section{ORIGEM}

A cultivar Leopoldina foi introduzida do "International Center for Agricultural Research in the Dry Areas" (ICRISAT), localizado na Índia. Ela foi recebida em 1991, com a denominação ICCV-3. Esta linhagem provém de um cruzamento múltiplo [( K 850 x GW 5/7 ) x P 458 ] x (L 550 x Guamuchil) feito em 1975, e foi selecionada para ter resistência à raça 1 da murcha-de-fusarium (Fusarium oxysporum f. sp. ciceri), na Índia.

\section{DESCRIÇÃO}

Plantada em abril ou maio e irrigada, a emergência ocorre entre 6 e 9 dias. Da emergência ao início da floração a 'Leopoldina' leva entre 43 e 63 dias, dependendo do local. O ciclo de vida varia de 125 a 135 dias. Apresenta plantas com tipo de crescimento ereto e in- serção da primeira vagem alta, o que facilita a colheita mecanizada. As plantas atingem 55 a $60 \mathrm{~cm}$ de altura. A flor é branca e o comprimento da vagem é de $25 \mathrm{~mm}$; em geral são produzidas 2 a 3 sementes por vagem. O índice de colheita normalmente varia de $37 \%$ a $48 \%$. As sementes têm coloração creme e o peso de 100 unidades varia de 28 a 36 g. A cultivar Leopoldina é resistente à raça 1 de $F$. oxysporum f. sp. ciceri e tolerante aos nematóides causadores de galhas nas raízes (informação pessoal, Dr. Jagdish Kumar, ICRISAT).

A cultivar Leopoldina teve bom desempenho quando plantada em abril ou maio na Zona da Mata e no Norte de Minas Gerais, sempre com irrigação. Em Coimbra, município da Zona da Mata localizado a $800 \mathrm{~m}$ de altitude, seu rendimento variou de 2.037 a 2.300 $\mathrm{kg} / \mathrm{ha}$ (Braga et al., 1997). Em Leopoldina, município da Zona da Mata localizado a $210 \mathrm{~m}$ de altitude, o rendimento atingiu $2.959 \mathrm{~kg} / \mathrm{ha}$. Em Janaúba, Norte de Minas Gerais, ela rendeu $2.640 \mathrm{~kg} / \mathrm{ha}$. Em média, a cultivar Leopoldina rendeu $20 \%$ e $42 \%$ a mais que as cultivares IAC Marrocos e Cícero, respectivamente. Nesses ensaios, a 'Leopoldina' foi plantada no 
espaçamento entre fileiras de $50 \mathrm{~cm}$, com 20 sementes por metro. A adubação nitrogenada de cobertura variou de 30 a $100 \mathrm{~kg} / \mathrm{ha}$ de N. Não se fez uso de inoculante (Bradyrhizobium sp.).

\section{DISPONIBILIDADE DE SE- MENTES}

Pequenas amostras de sementes da cultivar Leopoldina podem ser obtidas no Centro Tecnológico da Zona da Mata (EPAMIG), em Viçosa,MG.

\section{AGRADECIMENTOS}

Os autores agradecem à FAPEMIG pelo financiamento da pesquisa que teve como resultado o lançamento da cultivar Leopoldina.

\section{LITERATURA CITADA}

BRAGA, N.R., VIEIRA, R.F., RAMOS, J.A. de $\mathrm{O}$. A cultura do grão-de-bico. Informe Agropecuário, Belo Horizonte, v. 16, n. 174, p. $47-52,1992$.
BRAGA, N.R., VIEIRA, C., VIEIRA, R.F Comportamento de cultivares de grão-de-bico (Cicer arietinum L.) na Microrregião de Viçosa, Minas Gerais. Revista Ceres, Viçosa, v. 44, n. 255, p. 577-591, 1997.

GIORDANO, L. de B.; NASCIMENTO, W.M 'Cícero': nova cultivar de grão-de-bico para cultivo de inverno. Horticultura Brasileira, Brasília, v. 12, n. 1, p. 80 (Resumo), 1994. 